\title{
Pengembangan Desain Kerajinan Manik-Manik Kaca sebagai Tas Wanita
}

\author{
Rachmadhana Insan Chandravialissa dan Ellya Zulaikha \\ Departemen Desain Produk Industri, Fakultas Arsitektur, Desain dan Perencanaan, \\ Institut Teknologi Sepuluh Nopember (ITS) \\ e-mail: ellya.zulaikha@gmail.com
}

\begin{abstract}
Abstrak-Kerajinan manik-manik kaca merupakan salah satu mata pencaharian utama masyarakat di Desa Gambang, Kecamatan Gudo, Jombang, Jawa Timur yang pernah berkembang sangat pesat satu setengah dekade yang lalu. Namun karena kurangnya inovasi desain, industri ini terus mengalami penurunan. Hampir seluruh manik-manik kaca hanya menjadi produk perhiasan. Di sisi lain, keahlian pengrajin untuk membuat manik-manik dengan berbagai bentuk dan corak dapat dikembangkan menjadi produk seperti tas dan apparel lainnya. Berdasarkan situasi tersebut, penulis melakukan pengembangan desain melalui eksperimen bentuk dan manik-manik kaca untuk diterapkan pada produk tas, serta melakukan eksperimen aplikasi perangkaian manik-manik pada produk tas wanita. Ekplorasi bahan pada desain manik untuk tas ini adalah bahan kayu, kulit, dan rotan. Berdasarkan eksplorasi tersebut diketahui bahwa tas wanita berbahan rotan manik dengan konsep modern memiliki potensi kuat untuk dikembangkan lebih lanjut. jang abstrak yang disarankan adalah antara 100 hingga 300 kata.
\end{abstract}

Kata Kunci-Desain, Manik-manik kaca Jombang, Tas.

\section{PENDAHULUAN}

$\mathrm{S}$ ALAH satu kerajinan tangan di Indonesia yang dapat dikembangkan sebagai produk tas adalah kerajinan IKM dari material manik-manik kaca di Jombang. Manik adalah suatu benda yang biasanya berbentuk bulat, dilubangi dan dironce guna menghias badan atau sebuah benda [1]. Disana manik-manik kaca dibuat dengan besi berbagai ukuran dan cairan kaolin yang biasanya dirangkai menjadi perhiasan seperti kalung dan gelang. Berdasarkan buku Manik-Manik di Indonesia [1] disebutkan beberapa jenis manik-manik yaitu Manik berleher, teknik lapidary, manik monokrom, manik policrom, manik beruas-ruas, dan manik tabular. Semua jenis manik-manik diatas diproduksi oleh pengrajin di Gudo, Jombang.

Pada saat ini para pengrajin manik kaca di IKM Gudo, Jombang yang awalnya mencapai ribuan hanya tersisa puluhan pengrajin. Masalah yang disebabkan sama dengan kebanyakan IKM di Indonesia lainnya, yaitu minimnya pengetahuan pengrajin tentang desain. Hal ini menyebabkan pengrajin tidak tahu bagaimana harus mengembangkan varian desain dan tetap bertahan dengan desain yang lama dengan cara tradisional [2]. Karena keterbatasan tersebut, pengrajin manik-manik kaca lebih memilih mencontoh desain yang sudah ada di pasar sehingga tidak jarang manik-manik buatan Jombang ini dikenali sebagai manik-manik Bali, Kalimantan, atau bahkan Australia [3]. Padahal, manik-manik kaca dapat dikembangkan lagi berdasarkan bentuk, motif ataupun warna sehingga produk yang dihasilkan tidak hanya perhiasan.

Manik-manik kaca dapat memberikan kebaruan pada material yang digunakan untuk penghias tas, struktur tas atau aksesoris tas dengan karakter manik kaca yang mempunyai warna mengkilap dan warna yang tidak mudah memudar.

\section{METODE PENELITIAN}

Pengambilan data dimulai dengan studi literatur yang terkait dengan proses produksi manik-manik kaca, fashion style dan tas. Selanjutnya dilakukan wawancara dan observasi dengan pengrajin manik-manik yang diikuti dengan proses kolaborasi antara penulis dan pengrajin di Desa Gambang, Kec. Gudo, Jombang serta melakukan eksperimen material manik-manik kaca untuk menemukan kemungkinan baru dalam pengembangan desain manik-manik.

Studi yang dilakukan pada penelitian ini adalah:

1. Studi analisis material manik-manik kaca: diperlukan untuk mengetahui karakteristik dari manik-manik kaca.

2. Studi dan analisis material tambahan: menentukan material yang dapat digabungkan dengan manik-manik kaca.

3. Eksperimen bentuk manik-manik kaca: untuk mengetahui sejauh mana manik-manik kaca dapat dibentuk.

4. Eksperimen warna dan motif manik-manik kaca: untuk mengetahui warna dan motif apa saja yang dapat dihasilkan dengan mencampur beberapa warna atau mencampur bahan lain ke manik-manik.

5. Eksperimen perangkaian manik-manik kaca: mengetahui bagaimana cara merangkai manik-manik kaca dengan material lain sehingga tercipta suatu bentuk.

6. Studi analisis tas: menelaah bagian-bagian tas untuk mengetahui fungsi dan letaknya.

7. Analisis pasar: menganalisis pasar dengan metode STP atau Segmenting, Targeting dan Positioning.

8. Analisis persona: mengidentifikasi tipe pengguna dengan informasi usia, pekerjaan, nama fiktif, penghasilan, aktivitas dan desain yang disukai.

9. Studi analisis artefak: mengidentifikasi calon pengguna dalam menilai tas berdasarkan 3 unsur, yaitu behavioral, visceral dan reflektif

10. Studi analisis style: untuk mengetahui style fashion yang popular saat ini. 


\section{HASIL PENELITIAN}

\section{A. Hasil Eksperimen Manik-Manik Kaca}

\section{1) Eksperimen Bentuk}

Eksperimen ini bertujuan untuk mengetahui sejauh mana manik manik kaca dapat dibentuk sehingga dapat menghasilkan treatment yang paling sesuai dengan karakternya serta penyesuaian terhadap produk tas nantinya.

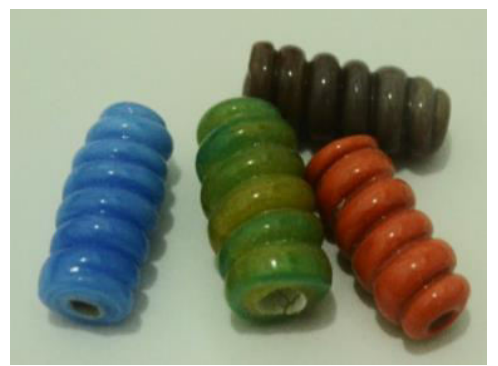

Gambar 1. Eksperimen bentuk dengan menggunakan kapi untuk membuat garis pada manik (Sumber: Penulis).

Penulis pada awalnya berkeinginan membuat bentuk manik yang ekstrim dengan bentuk yang abstrak pada bagian atas dan bawah manik kaca, akan tetapi pengrajin menerjemahkannya dalam bentuk di atas, mengingat kesulitan untuk membuat bentuk ekstrim itu terletak pada proses pembentukan. Saat kaca batangan telah dibentuk sesuai keinginan, besi yang terus berputar akan melelehkan kaca yang telah terbentuk tersebut karena terkena api dengan suhu yang tinggi.

Namun demikian, bentuk ini masih dapat dikembangkan lebih lanjut sebagai aksesoris tas, karena bentuk ini memiliki keunikan yang tidak banyak ditemui di pasar manik.

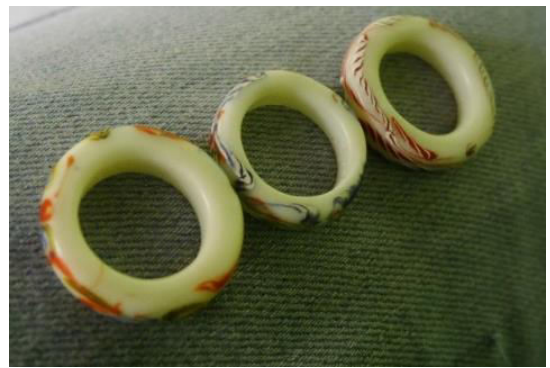

Gambar 2. Manik kaca berbentuk cincin yang menggunakan besi besar dan tidak menggunakan kaolin (Sumber: Penulis).

Jika manik-manik lain dibuat dengan besi berukuran 1-2 mm dan dengan cairan kaolin, manik-manik cincin dibuat dengan besi dan cairan yang berbeda. Maka dari itu tidak semua pengrajin dapat membuat bentuk ini. Membuat manikmanik dengan diameter besar mempunyai tantangan tersendiri karena manik kaca harus tebal sehingga tidak pecah nantinya.

Manik-manik cincin masih dapat dikembangkan motif dan warnananya sehingga dapat dikombinasikan dengan material lain sebagai aksesoris tas.

\section{2) Eksperimen Warna dan Motif}

Eksperimen warna dan motif pada material kaca dilakukan untuk mengeksplorasi kemungkinan hasil warna atau motif yang menarik dan dapat diekspos pada produk nantinya. Eksperimen ini memungkinkan untuk menggunakan material lain atau menggunakan kaca yang berukuran lebih kecil.

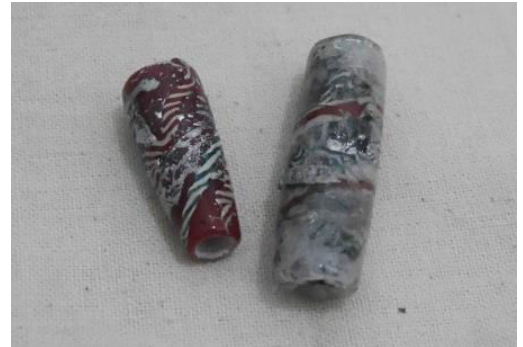

Gambar 3. Mencampur alumunium foil pada manik untuk memberikan motif yang berbeda (Sumber: Penulis).

Pada eksperimen ini, penulis mencoba mencampur manikmanik kaca dengan alumunium foil. Dipilih alumunium foil karena alumunium foil mempunyai suhu yang tahan panas sehingga ketika dilebur pada api dengan suhu $1000 \mathrm{C}$ tidak terbakar. Dengan mencampurkan manik-manik kaca dan alumunium foil berat manik-manik kaca menjadi lebih ringan serta menghasilkan motif yang unik dan belum pernah ada di pasar manik. Namun, hasil eksperimen pencampuran ini masih perlu dikembangkan lagi sehingga mencapai motif yang diinginkan.

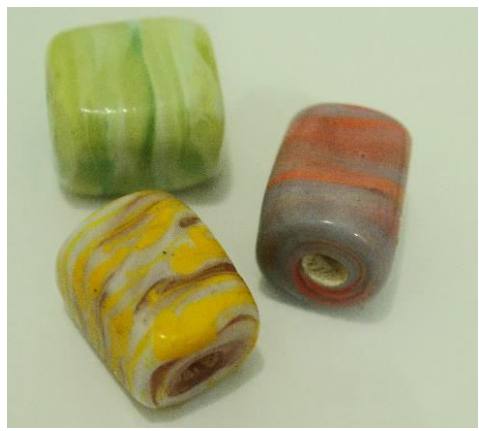

Gambar 4. Mencampur 3 kaca dengan warna berbeda (Sumber: Penulis).

Pada eksperimen ini penulis meminta pengrajin untuk mencoba mencampurkan 3 stick kaca dengan warna berbeda yang dibentuk persegi panjang. Warna dan motif yang dihasilkan sangat beragam mengingat terdapat beberapa warna yang dicampur menjadi satu. Cara membuat motif ini adalah dengan menggabungkan 3 stick kaca yang dilebur menjadi satu. Tidak semua pengrajin bisa melakukan hal ini, karena memegang beberapa stick kaca tidaklah mudah.

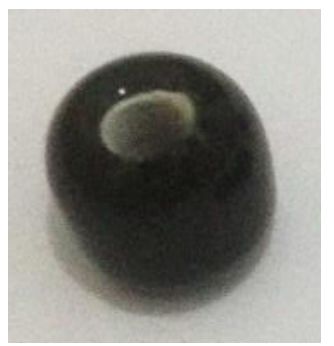

Gambar 5. Mencampur baking soda pada manik kaca tetapi tidak ada perubahan (Sumber: Penulis).

Penulis mencoba mencampur manik-manik dengan baking soda ketika dilebur dengan api. Namun tidak terjadi perubahan apapun pada manik-manik karena bahan baking soda tidak tahan terhadap suhu 1000 C. Maka dari itu jika ingin 
mencampur material lain ke dalam manik kaca harus dengan material yang tahan api.

\section{3) Eksperimen Perangkaian}

Eksperimen ini bertujuan untuk mengetahui sambungan seperti apa yang cocok dan dapat diterapkan pada mix material atau produk. Eksperimen ini menggunakan material lain yang memungkinkan untuk disambung pada material kaca.

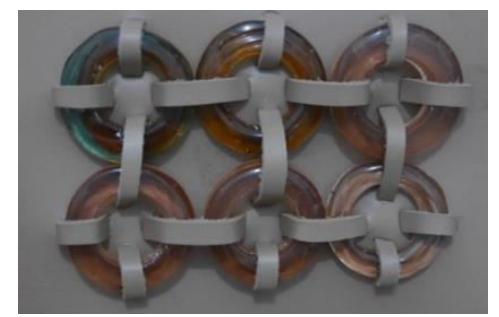

Gambar 6. Mencoba menganyam manik-manik dengan kulit sintetis (Sumber: Penulis).

Penulis mencoba merangkai manik-manik cincin pada kulit sintetis. Karena diameter manik cincin yang besar potongan kulit sintetis kecil digunakan untuk merangkai pada bagian atas, bawah, kanan, kiri manik pada kulit sintetis yang menjadi latar belakang.

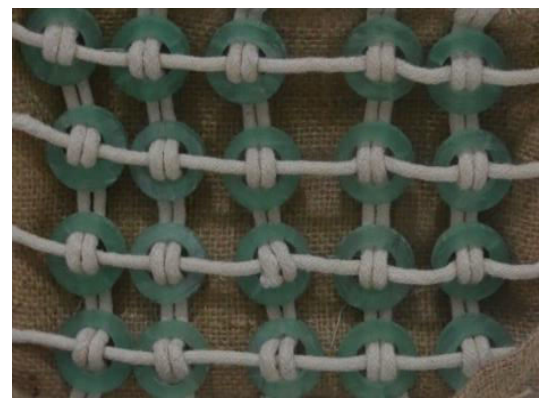

Gambar 7. Menggabungkan manik-manik dengan benang katun (Sumber: Penulis)

Pada eksperimen ini penulis mencoba merangkai manikmanik yang terbuat dari resin dengan tali katun dengan latar belakang karung goni. Hasil eksperimen ini masih perlu dikembangkan lagi dengan mencoba merangkai manik-manik, tali katun dan material lain pengganti karung goni yang lebih menarik.

\section{B. Pengaplikasian Manik-Manik pada Tas}

Setelah melakukan eksperimen dan menemukan manikmanik yang cocok, tahapan selanjutnya adalah proses pengaplikasian manik-manik pada tas. Dalam tahap ini terdapat beberapa proses diantaranya, 3D dan prototyping.

1) 3D Model

Sebelum membuat 3D penulis mencoba brainstorming dengan membuat sketsa sebanyak mungkin sampai menemukan bentuk yang diinginkan. Lalu dibuat bentuk 3D dari sketsa tersebut yang bertujuan untuk melihat sketsa dalam bentuk 3 dimensi sehingga mengetahui hasil akhir produk serta membantu dalam pembuatan prototype untuk pengrajin.

\section{2) Prototyping}

Proses terakhir adalah prototyping yaitu membuat produk skala 1:1 dari sketsa maupun 3D model ke pengrajin dan dilanjutkan menjahit lining ke penjahit. Untuk tas dari kayu lama pembuatan dari membuat manik-manik kaca hingga menjahit lining mencapai seminggu lebih. Sedangkan untuk prototype dari rotan memakan waktu 3-4 hari.

a. Kain

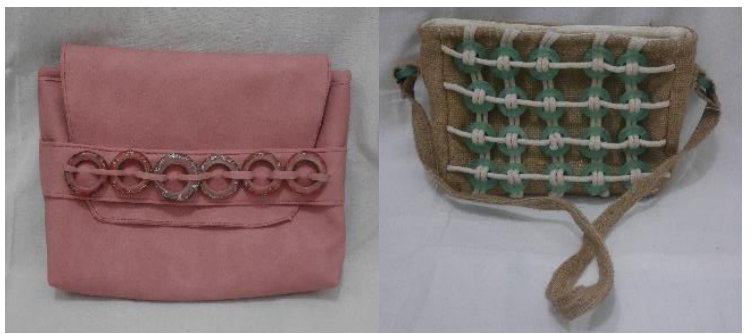

Gambar 8. Prototype tas kombinasi manik-manik dengan kulit sintetis(kiri) dan karung goni(kanan) (Sumber: Penulis).

Dalam pembuatan prototype ini, penulis mencoba menggabungkan dua elemen yaitu manik-manik dan kain. Prototype pertama manik-manik dirangkai dengan kulit sintetis sehingga menjadi strap untuk clutch. Sedangkan untuk prototype kedua penulis mencoba menggabungkan manikmanik resin yang telah dirangkai dengan tali katun dan dijahit pada bagian depan sling bag. Pada pembuatan prototype ini kesulitannya terletak pada perangkaian manik dan kain agar terlihat rapi.

Untuk biaya pembuatan prototype dengan pengaplikasian manik pada material kain tidak terlalu banyak memakan biaya karena material yang digunakan dan biaya jasa penjahit tidak terlalu mahal. Selain itu waktu yang dibutuhkan tergolong cepat sekitar 4-5 hari.

Namun, prototype ini masih perlu dikembangkan lagi sehingga mencapai hasil yang diinginkan.

b. Kayu

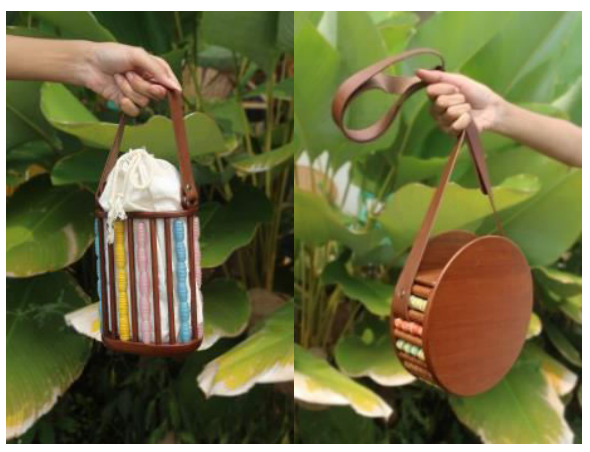

Gambar 13. Prototype tas kombinasi manik-manik dan kayu (Sumber: Penulis).

Pada awalnya, penulis menggunakan kayu pinus untuk clutch, namun setelah melihat motif dan kekuatan pinus yang kurang, material kayu pinus diganti menjadi kayu jati untuk sling bag dan handbag. Untuk prorotype ini manik-manik dirangkai seperti sempoa menggunakan kayu atau besi. Bentuk manik yang tidak sama membuat kayu yang digunakan untuk badan tas dipotong saat manik-manik telah jadi agar ukuran keduanya sama. Finishing yang digunakan menyerupai warna kayu jati dan menonjolkan motif dari kayu tersebut. Proses pembuatan prototype ini memakan waktu 8-9 hari dari pembuatan manik hingga menjahit inner lining pada tas. 
Untuk biaya pembuatan prototype dengan pengaplikasian manik pada material kayu tergolong mahal, karena selain harga kayu yang tidak murah, kain untuk dalaman tas serta kulit untuk strap dipilih dengan kualitas baik yang cocok dan setara dengan kayu jati.

Desain dari prototype kayu masih dapat dikembangkan lagi dari segi bentuk manik dan kayu sehingga dapat laku di pasaran.

\section{c. Rotan}

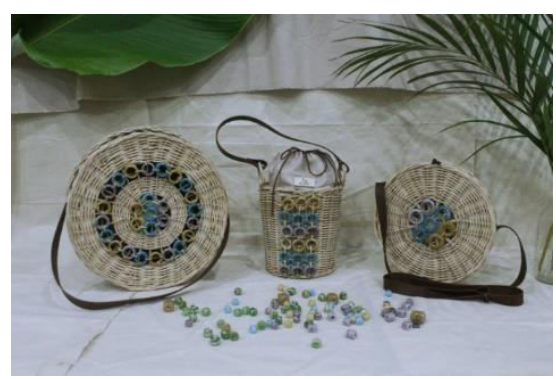

Gambar 14. Prototype tas kombinasi manik-manik dan rotan (Sumber: Penulis).

Penulis mencoba mengaplikasikan manik-manik pada rotan untuk prototype ke 3. Rotan dipilih karena strukturnya yang kuat dan dapat dianyam dengan material manik-manik kaca. Dalam prototype ini penulis membuat tas handbag, sling bag dan totebag yang menghabiskan waktu sekitar 4 hari dari proses pembuatan manik hingga menjahit lining tas. Proses pembuatan prorotype ini tergolong cepat karena membuat manik-manik dan menganyam rotan dapat dilakukan pada waktu yang bersamaan.

Biaya pembuatan prototype ini tergolong murah karena harga rotan dan material tambahan lainnya seperti kain dan kulit tidak terlalu memakan biaya.

Namun untuk membuat prototype dengan harga yang tinggi, tas dengan pengaplikasian manik pada rotan masih perlu diperbaiki dari segi finishing maupun pemilihan material tambahan seperti kain dan kulit.

\section{KESIMPULAN}

Berdasarkan data dan pembahasan mengenai eksperimen manik-manik kaca yang dikembangkan menjadi produk tas, kesimpulan yang dapat diambil adalah sebagai berikut:

Rotan merupakan bahan kombinasi yang paling berpotensi untuk dikembangkan lebih lanjut, mengingat belum ada kompetitor kombinasi rotan dan manik, biaya produksi rotan juga lebih kompetitif dibandingkan bahan kayu dan kulit. Untuk waktu pengerjaannya, prototype dengan kombinasi rotan tergolong cepat serta kemungkinan ekplorasi perangkaian manik dan rotan masih sangat besar.

Namun demikian, jika menggunakan bahan rotan maka tantangan pengerjaannya, terletak pada proses perangkaian dan proses finishing rotan dan manik yang harus sangat teliti dan rapi.

\section{UCAPAN TERIMA KASIH}

Penulis mengucapkan terima kasih kepada Sheffield Hallam University yang telah memberikan dukungan finansial sehingga penelitian ini dapat berjalan lancar. Serta pengrajin manik-manik kaca Jombang, pengrajin kayu, pengrajin rotan, penjahit, keluarga, yang telah membantu dalam pengerjaan Tugas Akhir ini.

\section{DAFTAR PUSTAKA}

[1] S. Adyatman and R. Arifin, Manik-Manik di Indonesia. Semarang: Djambatan, 1996.

[2] E. Zulaikha, "Transformasi IKM Kerajinan Tradisional Menjadi Industri Kreatif," 2005.

[3] I. C. Septanti and E. Naharani, "Desain Elemen Fashion Berbahan Manik-Manik Kaca Jombang sebagai Produk Ikonik dengan Konsep Kontemporer,” 2012. 